\title{
Blood Volume in Patients with Cervical Spinal Cord Injury
}

\author{
TOMOYUKi ITO, MD ${ }^{1,2)}$, YUKIHARU HigUCHI ${ }^{1)}$, HiROAKI BANNO, $\mathrm{PT}^{1)}$, \\ TAKASHI MizUSHIMA, PhD, MD ${ }^{2)}$, HiROMITSU KIMURA, MD ${ }^{1)}$, FUMIHIRO TAJIMA, PhD, MD ${ }^{3)}$ \\ 1) Ito National Rehabilitation Center for Severely Injured Persons \\ ${ }^{2)}$ Department of Rehabilitation, Hamamatsu University School of Medicine: \\ 1-20-1 Handayama, Hamamatsu, Shizuoka 431-3192, Japan. \\ TEL +81 53-435-2746 FAX +81 53-435-2747 E-mail: rinito@hama-med.ac.jp \\ ${ }^{3)}$ Department of Rehabilitation, Wakayama Medical College
}

J. Phys. Ther. Sci.

16: $81-84,2004$

\begin{abstract}
Blood volume is influenced by physical activity. Physical activity in patients with spinal cord injury is lower than able-bodied individuals and associated with the level of lesion. We hypothesized that blood volume in patients with cervical spinal cord injury might be lower than able-bodied individuals and influenced by the level of lesion. To eliminate the effect of the lesion level, we determined blood volume by Evans blue dilution technique in 9 male patients with cervical spinal cord injury (age; $25.9 \pm 1.9$ years, mean \pm SEM) whose level of lesions were $\mathrm{C} 6$ and compared them with 5 male able-bodied individuals (age; $27.6 \pm 1.9$ ). Plasma volume and blood volume in patients with cervical spinal cord injury were similar to those in able-bodied individuals. Despite the lower activity level of patients with cervical spinal cord injury in a wheelchair, blood volume did not change. Maintenance of blood volume in patients with cervical spinal cord injury is probably due to a reduction of central blood volume. The mechanism underlying reduced central blood volume appears to be lower vessel tension caused by autonomic nervous system dysfunction and/or lack of the muscle pump below the level of spinal cord lesion.
\end{abstract}

Key words: Sympathetic dysfunction, Stroke volume, Mean arterial pressure

(This article was submitted Feb. 10, 2004, and was accepted Apr. 14, 2004)

\section{INTRODUCTION}

Functional voluntary muscle mass and physical activity $^{1)}$ are reduced in patients with spinal cord injury (SCI) compared with able-bodied individuals $(\mathrm{AB})$, and in addition, they are affected by the level of spinal cord lesion in SCI. Blood volume (BV) increases with physical conditioning, and a fall in $\mathrm{BV}$ is observed with physical inactivity ${ }^{2,3)}$ in $\mathrm{AB}$. Several studies have examined the BV changes in patients with $\mathrm{SCI}^{4-7)}$. In patients with SCI ranging from $\mathrm{C} 5$ to $\mathrm{L} 1, \mathrm{BV}$ was reported to be lower than in $\mathrm{AB}^{4,5)}$. BV in SCI was also reported to be increased after 6 weeks of electrical stimulation and leg cycling training ${ }^{4}$, but not after 6 weeks of arm- cranking training 5 ). On the other hand, others have reported that $\mathrm{BV}$ was within the normal range in patients with cervical SCI $(\mathrm{CSCI})^{6,7)}$.

We postulated that the level of spinal cord lesion and physical activity influence $\mathrm{BV}$ and it is especially lower than $\mathrm{AB}$ when the level of lesion is high. To our knowledge, no study has determined $\mathrm{BV}$ in CSCI with a similar level of spinal cord lesion. Also, BV in CSCI during the chronic phase has not been compared with AB using the same method, and in addition, Evans blue dilution technique was not used in any study. The aim of the present study was to compare BV in CSCI measured by the Evans blue dilution technique with $\mathrm{AB}$. To determine $\mathrm{BV}$ in $\mathrm{CSCI}$, moreover, to 
eliminate the effect of the lesion level and physical activity, we selected patients with CSCI whose level of lesions were C6, and also who were similarly physically active.

\section{METHODS}

\section{Subjects}

Nine male CSCI (age; $25.9 \pm 1.9$ years, mean \pm SEM, American Spinal Injury Association [ASIA] Class A; level of lesion, C6, the lowest normal motor segment) and 5 male AB (age, $27.6 \pm 1.9$ ) participated in this study. All patients were in stable condition and the mean time since injury was $5.3 \pm$ 1.2 years. All CSCI patients were receiving training through an active rehabilitation program (5 days a week for the preceding $2.1 \pm 0.5$ years). The physical characteristics of each subject are shown in Table 1. All subjects in this study were free of acute and chronic diseases and had negative medical histories apart from the spinal injuries. None was on medication except for a purgative given at the time of the study in order to prevent possible constipation that may affect the function of the autonomic nervous system. Physical examination, including an electrocardiogram, was conducted by a physician, who confirmed that all subjects were in good general health. Written informed consent was obtained from each subject before participation in the study. This study was approved by the Review Board on Human Experiments of Ito National Rehabilitation Center for Severely Disabled Persons.

\section{Determination of blood volume}

BV was determined by the Evans Blue dye dilution technique. $\mathrm{CSCI}$ and $\mathrm{AB}$ reported to the laboratory after fasting for at least $8 \mathrm{~h}$ to reduce plasma turbidity. After reporting to the laboratory, the subject sat on a chair for $30 \mathrm{~min}$ to stabilize body fluid movement across various fluid compartments. Subsequently, a 20-gauge catheter was inserted into the antecubital vein, and a control blood sample was withdrawn immediately after the end of the rest period. Then, a known amount of Evans Blue dye ( $15 \mathrm{mg}$; New World Corp., FL) was injected through the catheter, and blood samples were collected at 10 and $20 \mathrm{~min}$ after the injection. To eliminate the time-dependent changes in plasma absorbance caused by turbidity, we measured absorbance of plasma at $620 \mathrm{~nm}$ and 740
Table 1. Physical characteristics of subjects

\begin{tabular}{lrc}
\hline & CSCI $(\mathrm{n}=9)$ & AB $(\mathrm{n}=5)$ \\
\hline Age $(\mathrm{yr})$ & $25.9 \pm 1.9$ & $27.6 \pm 1.9$ \\
Height $(\mathrm{cm})$ & $170.9 \pm 2.0$ & $169.0 \pm 2.4$ \\
Weight $(\mathrm{kg})$ & $54.5 \pm 2.1$ & $64.0 \pm 3.6^{*}$ \\
Vital capacity (L) & $2.4 \pm 0.2$ & $4.4 \pm 0.2^{*}$ \\
HR (beat/min) & $67.3 \pm 1.3$ & $76.4 \pm 5.9$ \\
MAP (mmHg) & $77.3 \pm 4.1$ & $94.4 \pm 1.4^{*}$ \\
\hline
\end{tabular}

$\mathrm{CSCI}$, patients with cervical spinal cord injury; $\mathrm{AB}$, ablebodied individuals. HR, heart rate; MAP, mean arterial pressure. Values are mean \pm SEM. *indicate the significant difference between CSCI and AB.

nm (Spectrophotometer U-1500, Hitachi, Tokyo). We then estimated the plasma absorbance at $620 \mathrm{~nm}$ of the $10-\mathrm{min}$ and 20 -min samples from the regression equation between $620 \mathrm{~nm}$ and $740 \mathrm{~nm}$ obtained from the control plasma of 64 subjects ${ }^{8,9)}$. The equation obtained from our control subjects was:

$\mathrm{Abs}_{740 \mathrm{~nm}}=0.781 \times \mathrm{Abs}_{620 \mathrm{~nm}}-0.0177(\mathrm{r}=0.99)$, where $A b s_{740} \mathrm{~nm}$ is plasma absorbance at $740 \mathrm{~nm}$, and $\mathrm{Abs}_{620 \mathrm{~nm}}$ is absorbance of plasma at $620 \mathrm{~nm}$.

Hematocrit (Hct) was determined in triplicate by the capillary centrifugation method, and hemoglobin concentration $(\mathrm{Hb})$ was measured by a cyanmethemoglobin method (Hb test Wako, Wako Chemical, Tokyo). BV was calculated as $\mathrm{BV}=\mathrm{PV} \times\left(1-\mathrm{Hct} \times 0.97 \times 0.91 \times 100^{-1}\right)^{-1}$ where PV is plasma volume, 0.97 is correction for $3 \%$ trapped plasma and 0.91 is the F-cell ratio ${ }^{10)}$.

\section{Data and statistical analyses}

Data are expressed as mean \pm SEM. Differences in variables between $\mathrm{CSCI}$ and $\mathrm{AB}$ were tested for statistical significance by analysis of variance (ANOVA). Post Hoc Fisher's protected least significant difference test was used when the $\mathrm{F}$ ratio was significant. $P$ values $<0.05$ were considered significant.

\section{RESULTS}

Heart rate (HR) and mean arterial pressure (MAP) at rest are shown in Table 1. HR in CSCI was similar to that in $\mathrm{AB}$, however, MAP in CSCI was significantly lower than AB.

Table 2 shows plasma volume (PV) and BV in CSCI and AB. PV and BV values were not significantly different from those of AB. 
Table 2. Plasma volume and blood volume

\begin{tabular}{lcc}
\hline & CSCI $(\mathrm{n}=9)$ & $\mathrm{AB}(\mathrm{n}=5)$ \\
\hline Plasma volume $(\mathrm{ml})$ & $2553.0 \pm 91.1$ & $2734.9 \pm 139.0$ \\
Blood volume $(\mathrm{ml})$ & $4220.1 \pm 123.3$ & $4526.7 \pm 229.7$ \\
Plasma volume $\left(\mathrm{ml} \cdot \mathrm{kg}^{-1}\right)$ & $47.3 \pm 2.1$ & $42.9 \pm 1.6$ \\
Blood volume $\left(\mathrm{m} \cdot \mathrm{kg}^{-1}\right)$ & $79.6 \pm 3.2$ & $70.9 \pm 2.0$ \\
\hline
\end{tabular}

CSCI, patients with cervical spinal cord injury; AB, able-bodied individuals. Values are mean \pm SEM.

Furthermore, $\mathrm{Hb}$ in CSCI $(14.3 \pm 0.3 \mathrm{~g} / \mathrm{dl})$ was also similar to AB $(14.6 \pm 0.6 \mathrm{~g} / \mathrm{dl})$. We compared PV and BV per body weight in both groups (Table 2), because body weight of $\mathrm{AB}$ was significantly higher than that of CSCI. Interestingly, neither PV nor BV was significantly different between the two groups.

\section{DISCUSSION}

The major finding of the present study was BV in CSCI whose lesion level was C6 and who were relatively active was similar to that in $\mathrm{AB}$.

In previous studies, BV was measured in subjects with SCI by using the carbon monoxide method and was reported to be lower in $\mathrm{SCI}$ than $\mathrm{AB}^{4,5)}$. While the spinal cord lesions in the subjects of these studies ranged from $\mathrm{C} 5$ to $\mathrm{L} 1$, the level of lesion in our subjects was only C6. The variable level of spinal cord lesion in other studies and the use of a different method to measure BV might explain the lower BV in the aforementioned studies. On the other hand, Huang et al. ${ }^{7)}$ and Desmond and Laws ${ }^{6}$ ) measured $\mathrm{BV}$ in CSCI and reported that it was within the normal range. In our study, BV in CSCI was within the range of $\mathrm{BV}$ reported for $\mathrm{CSCI}$ in the above studies ${ }^{6,7)}$. In their studies, however, BV was not measured in $\mathrm{AB}$ using the same method. In the present study, the clinical characteristics of subjects with CSCI were arranged to be in the same level of spinal cord injury (i.e., C6 complete quadriplegia). Also, our subjects participated in rehabilitation programs at least 5 times per week, and the same methods were used to measure $\mathrm{BV}$ in $\mathrm{AB}$ and CSCI. Furthermore, our subjects with CSCI were in a stable condition with respect to CSCI. Huang et al. reported that normal $\mathrm{BV}$ levels during the acute phase of CSCI were probably maintained by increased $\mathrm{PV}^{7)}$. However, our results showed no significant difference in PV between CSCI and AB.
Based on these results, we believe the following compensatory changes occur in CSCI. Vasodilation occurs in peripheral vessels below the level of spinal cord lesion, possibly due to impaired function of the sympathetic nervous system. This leads to a decrease in central blood volume, which ultimately results in an increase or maintenance of $\mathrm{PV}$ and $\mathrm{BV}$ in CSCI, irrespective of the duration of lesion (i.e., acute or chronic). These changes could occur in our CSCI patients even though their physical activity was lower than $\mathrm{AB}$ and they spent most of the study time sitting in a wheelchair, which hydrostatic pressure should be lower than that generated in the standing position.

A reduction of stroke volume (SV) associated with reduced $\mathrm{BV}$ contributes to ineffective maintenance of arterial blood pressure in $\mathrm{AB}^{11)}$. Although $\mathrm{BV}$ in CSCI was similar to that in $\mathrm{AB}$, MAP was significantly lower in CSCI (Table 1). And in addition, HR did not differ between CSCI and $\mathrm{AB}$. We measured their blood pressure in the sitting position. Yamamoto et al. ${ }^{12)}$ also reported that similar HR in CSCI to AB was observed, and MAP in CSCI was lower compared with $\mathrm{AB}$ at rest. And in addition, plasma concentration of norepinephrine and epinephrine were significantly lower in CSCI than in AB. These results may suggest that lower MAP in CSCI is due to lack of peripheral vasoconstriction because of the absence of the sympathetic nervous system ${ }^{12-14)}$ and activation of the pump muscles below the level of spinal cord lesion ${ }^{13)}$. Without the vasoconstriction and/or muscle pump in CSCI, though BV was similar to $A B$, venous return decreases, hence $S V$ and MAP are lower in CSCI than in AB.

In conclusion, this is the first study to compare $\mathrm{BV}$ in well-trained patients with stable CSCI whose level of lesion was $\mathrm{C} 6$ with that in $\mathrm{AB}$, using the same method. Our results show that BV in CSCI was similar to that in AB. However MAP in CSCI was lower than AB. These results might be due to lower central blood volume associated with dysfunction of the sympathetic nervous system in CSCI.

\section{ACKNOWLEDGEMENT}

This study was supported in part by a Grant-inAid from the Ministry of Health, Labor and Welfare, Japan. 


\section{REFERENCES}

1) Barstow TJ, Scremin AM, Mutton DL, et al.: Peak and kinetic cardiorespiratory responses during arm and leg exercise in patients with spinal cord injury. Spinal Cord, 2000, 38: 340-345.

2) Convertino VA: Blood volume: its adaptation to endurance training. Med Sci Sports Exerc, 1973, 23: 1338-1348.

3) Cullinane EM, Sady SP, Vadeboncoeur L, et al.: Cardiac size and $\mathrm{VO}_{2}$ max do not decrease after shortterm exercise cessation. Med Sci Sports Exerc, 1986, 18: $420-424$.

4) Houtman S, Oeseburg B, Hopman MT: Blood volume and hemoglobin after spinal cord injury. Am J Phys Med Rehabil, 2000, 79: 260-265.

5) Knutsson E, Lewenhaupt-Olsson E, Thorsen M: Physical work capacity and physical conditioning in paraplegic patients. Paraplegia, 1973, 11: 205-216.

6) Desmond JW, Laws AK: Blood volume and capacitance vessel compliance in the quadriplegic patient. Can Anaesth Soc, 1974, J 21: 421-426.

7) Huang CT, DeVivo MJ, Stover SL: Anemia in acute phase of spinal cord injury. Arch Phys Med Rehabil, 1990, 71: 3-7.
8) Foldager N, Blomqvist CG: Repeated plasma volume determination with the Evans Blue dye dilution technique: the method and a computer program. Comput Biol Med, 1991, 27: 35-41.

9) Ito T, Takamata A, Yaegashi K, et al.: Role of blood volume in the age-associated decline in peak oxygen uptake in humans. Jpn J Physiol, 2001, 51: 607-612.

10) Greenleaf JE, Convertino VA, Mangseth GR: Plasma volume during stress in man: osmolality and red cell volume. J Appl Physiol, 1979, 47: 1031-1038.

11) Convertino VA: Mechanisms of microgravity induced orthostatic intolerance implications for effective countermeasures. J Gravit Physiol, 2002, 9: 1-13.

12) Yamamoto $M$, Tajima F, Okawa H, et al.: Static exercise -induced increase in blood pressure in individuals with cervical spinal cord injury. Arch Phys Med Rehabil, 1990, 80: 288-293.

13) Hopman MT, Monroe M, Dueck C, et al.: Blood redistribution and circulatory responses to submaximal arm exercise in persons with spinal cord injury. Scand J Rehabil Med, 1998, 30: 167-474.

14) Rowell LB, DS O'Leary: Reflex control of the circulation during exercise: chemoreflex and mechanoreflexes. J Appl Physiol, 1990, 69: 407-418. 